Provided for non-commercial research and education use. Not for reproduction, distribution or commercial use.

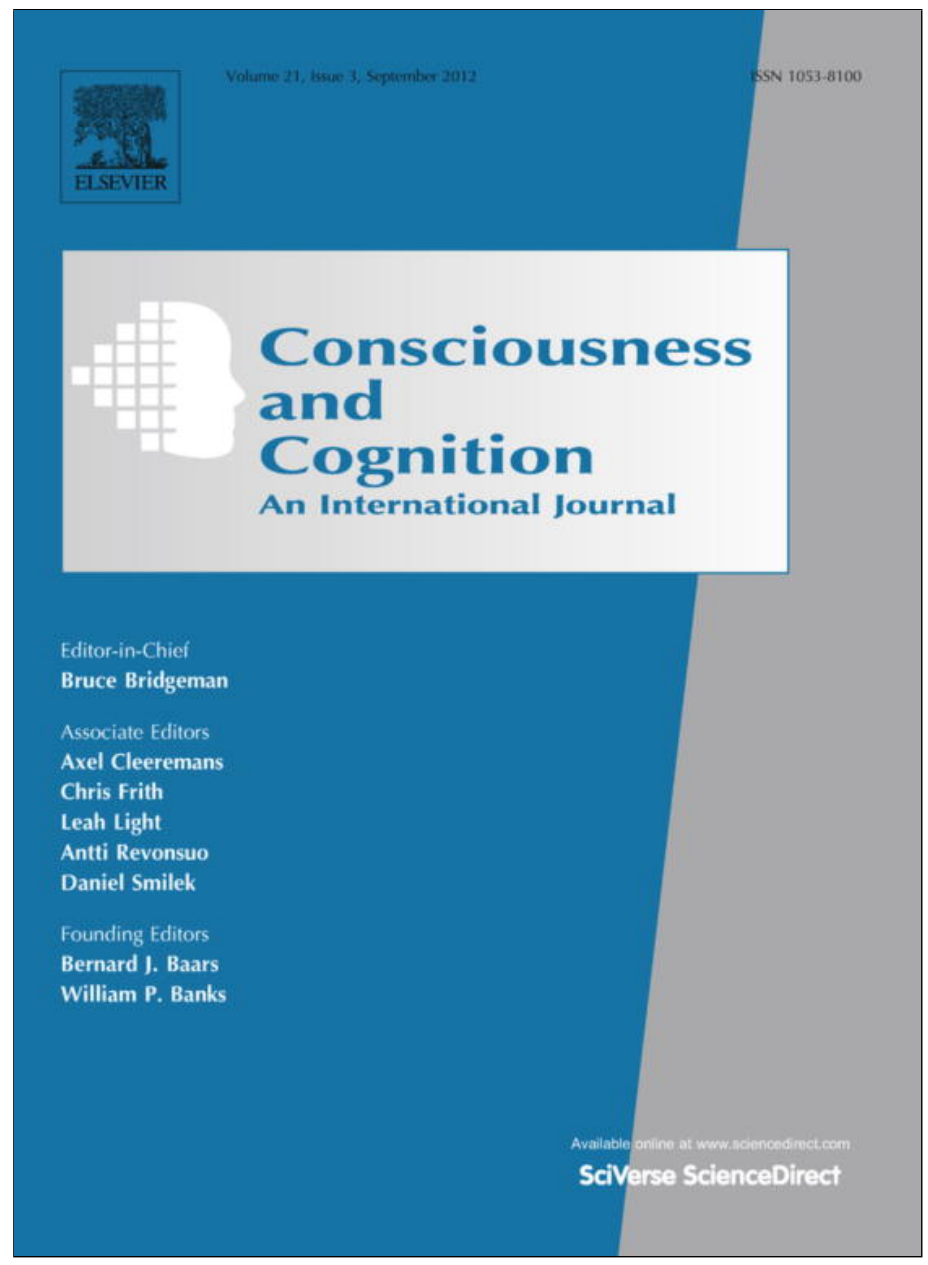

This article appeared in a journal published by Elsevier. The attached copy is furnished to the author for internal non-commercial research and education use, including for instruction at the authors institution and sharing with colleagues.

Other uses, including reproduction and distribution, or selling or licensing copies, or posting to personal, institutional or third party websites are prohibited.

In most cases authors are permitted to post their version of the article (e.g. in Word or Tex form) to their personal website or institutional repository. Authors requiring further information regarding Elsevier's archiving and manuscript policies are encouraged to visit:

http://www.elsevier.com/copyright 
Commentary

\title{
The magnitude of priming effects is not independent of prime awareness. Reply to Francken, van Gaal, \& de Lange (2011)
}

\author{
Kobe Desender ${ }^{\mathrm{a}}$, Eva Van den Bussche ${ }^{\mathrm{b}, *}$ \\ a Department of Experimental Psychology, Ghent University, Ghent, Belgium \\ ${ }^{\mathrm{b}}$ Department of Psychology, Vrije Universiteit Brussel, Brussels, Belgium
}

An unconscious prime typically affects responding to a subsequently presented target to a lesser extent, than a consciously perceived prime. A frequent observation is that several higher cognitive effects are observed solely with conscious primes. For example, using the priming paradigm, unconscious primes have proven to cause significantly smaller priming effects on the current trial (e.g. Dehaene et al., 2003), and smaller (van Gaal, Lamme, \& Ridderinkhof, 2010) or even absent (Kunde, 2003) sequential modulation effects on the next trial, compared to conscious primes. However, a potential problem is that the signal strength always critically differed between both conditions (Lau, 2009). In other paradigms, such as binocular rivalry, the signal strength of the conscious and the unconscious percept is perfectly matched (e.g. Tong, Nakayama, Vaughan, \& Kanwisher, 1998). Different information is presented to each eye, and both sources of information reach consciousness alternatingly. Primes with equal signal strength can be presented consciously or unconsciously by presenting them to either the suppressed or the dominant eye field (Cave, Blake, \& McNamara, 1998). However, in the priming paradigm this is usually not the case. In this paradigm, to create an unconscious condition, the prime is typically followed by a mask, which blocks any further prime processing, and which is typically omitted in the conscious condition. As a consequence, the signal strength of the prime in the conscious condition is much stronger, and larger priming effects can be caused by differences in signal strength.

This important issue has not received much attention within this field. However, Francken, van Gaal, and de Lange (2011) finally brought it to mind properly. They matched the signal strength of prime arrows by masking them with either an effective metacontrast target or a less-effective pseudomask target. As foreseen, the visibility of the primes was much lower with a metacontrast target, creating an unconscious condition. The authors found that the priming effect on the current trial was identical in both errors and reaction times for the conscious and unconscious condition. Furthermore, in the errors the decrease of the priming effect when the previous trial was incongruent (Gratton, Coles, \& Donchin, 1992) was also identical in both conditions. Based on this, the authors claimed that priming effects are independent of prime awareness.

We fully agree that Francken et al. addressed an important issue, which previous research has largely overlooked. Nevertheless, we want to argue that their conclusions are premature, due to methodological issues. In the literature, an influential view suggests that the difference between conscious and unconscious processing is an all-or-none phenomenon (e.g. Sergent \& Dehaene, 2004a, 2004b). Thus, efforts should be made to compare conscious with truly unconscious conditions. Unfortunately, in Francken et al. the visibility in the metacontrast condition was too high $\left(d^{\prime}=0.89\right)$ to be considered unconscious. Moreover, in the prime discrimination task, next to left and right pointing targets, a square-shaped target was presented (both as metacontrast and pseudomask), which was not used in the main experiment. This square-shaped target caused large visibility differences when presented as a metacontrast compared to pseudomask, and thus artificially

Commentary on Francken, J. C., van Gaal, S., \& de Lange, F. P. (2011). Immediate and long-term priming effects are independent of prime awareness. Consciousness and Cognition, 20, 1793-1800.

* Corresponding author. Address: Faculty of Psychology and Educational Sciences, Vrije Universiteit Brussel, Pleinlaan 2, 1050 Brussels, Belgium. Fax: +32 (0)2 6292489 .

E-mail address: Eva.Van.den.Bussche@vub.ac.be (E. Van den Bussche). 
magnified the difference between both conditions in the experiment. Consequently, the true difference in visibility between the two conditions, computed without these masks, was much smaller than the suggested difference. ${ }^{1}$ Thus, it appears that the authors created two conscious conditions instead of a conscious and unconscious condition. Of course, taking this into account, the current observation of identical priming effects in both conditions is not surprising. Because of these methodological problems, the conclusion that priming is independent of prime awareness is premature. Additionally, although both masks were physically virtually similar, they critically differed in masking the direction of the prime. Therefore, in our opinion the signal strength of the prime was still higher with a pseudomask compared to a metacontrast mask.

Although priming effects can be enlarged by changing the SOA, without altering prime recognition (Vorberg, Mattler, Heinecke, Schmidt, \& Schwarzbach, 2003), and identical priming effects can be obtained with differing degrees of prime visibility (Lau \& Passingham, 2006; Schlaghecken, Blagrove, \& Maylor, 2008), none of these studies convincingly showed that priming is completely independent of awareness. On the contrary, we would like to argue that priming effects are highly dependent on prime visibility. In a recent priming study (Van den Bussche \& Reynvoet, October 2011), we displayed the prime for an intermediate duration $(40 \mathrm{~ms})$, so that primes were unconscious on some trials and conscious on others. Prime visibility was measured after each trial. Trials where subjects did not perceive the prime were categorized as unconscious. Trials where subjects correctly identified the prime and were certain of their answer were categorized as conscious. This way, all possible features, including signal strength, are perfectly matched between the conscious and unconscious condition. In this study, large priming effects were observed, which were modulated by the visibility of the primes. Although robust priming was observed in both conditions, the $140 \mathrm{~ms}$ priming effect in the conscious condition was significantly larger than the $33 \mathrm{~ms}$ effect in the unconscious condition $(t(36)=4.02, p=.001)$. The error data perfectly mimicked these results. So, we can conclude that the magnitude of priming effects is certainly not independent of prime awareness. Consciously perceiving a prime leads to a late and sustained increase in sensory processing (Haynes, Driver, \& Rees, 2005; Sergent \& Dehaene, 2004a), which boosts performance enormously.

In summary, previous research failed to match the signal strength between the conscious and unconscious condition, which introduces an important confound in the literature. We would like to stress that Francken et al. (2011) addressed a very important issue, which needs to receive profound attention in future research. However, methodological issues undermine the reliability of their results. Based on our recent findings, we conclude that the magnitude of priming effects is highly dependent on prime visibility, even when stimulus strength is matched.

\section{References}

Cave, C. B., Blake, R., \& McNamara, T. P. (1998). Binocular rivalry disrupts visual priming. Psychological Science, 9, $299-302$.

Dehaene, S., Artiges, E., Naccache, L., Martelli, C., Viard, A., Schürhoff, F., et al (2003). Conscious and subliminal conflicts in normal subjects and patients with schizophrenia: The role of the anterior cingulate. Proceedings of the National Academy of Sciences of the United States of America, $100,13722-13727$.

Francken, J. C., van Gaal, S., \& de Lange, F. P. (2011). Immediate and long-term priming effects are independent of prime awareness. Consciousness and Cognition, 20, 1793-1800.

Gratton, G., Coles, M. G. H., \& Donchin, E. (1992). Optimizing the use of information: Strategic control of activation of responses. Journal of Experimental Psychology: General, 121, 480-506.

Haynes, J. D., Driver, J., \& Rees, G. (2005). Visibility reflects dynamic changes of effective connectivity between V1 and fusiform cortex. Neuron, 46, 811-821.

Kunde, W. (2003). Sequential modulations of stimulus-response correspondence effects depend on awareness of response conflict. Psychonomic Bulletin Review, 10, 198-205.

Lau, H. C. (2009). Volition and the functions of consciousness. In M. Gazzaniga (Ed.), The cognitive neurosciences IV. Boston: MIT Press.

Lau, H. C., \& Passingham, R. E. (2006). Relative blindsight in normal observers and the neural correlate of visual consciousness. Proceedings of the National Academy of Sciences of the United States of America, 103, 18763-18768.

Schlaghecken, F., Blagrove, E., \& Maylor, E. A. (2008). No difference between conscious and nonconscious visuomotor control: Evidence from perceptual learning in the masked prime task. Consciousness and Cognition, 17, 84-93.

Sergent, C., \& Dehaene, S. (2004a). Neural processes underlying conscious perception: Experimental findings and a global neuronal workspace framework. Journal of Physiology Paris, 98, 374-384.

Sergent, C., \& Dehaene, S. (2004b). Is consciousness a gradual phenomenon? Evidence for an all-or-none bifurcation during the attentional blink. Psychological Science, 15, 720-728.

Tong, F., Nakayama, K., Vaughan, J. T., \& Kanwisher, N. (1998). Binocular rivalry and visual awareness in human extrastriate cortex. Neuron, 21, 753-759.

Van den Bussche, E., \& Reynvoet, B. (2011). How to measure unconscious perception? A trial-based assessment approach. Unpublished paper presented at the European Society for Cognitive Psychology conference, San Sebastian, Spain

van Gaal, S., Lamme, V. A. F., \& Ridderinkhof, K. R. (2010). Unconsciously triggered conflict adaptation. PLOS One, 5, e11508.

Vorberg, D., Mattler, U., Heinecke, A., Schmidt, T., \& Schwarzbach, J. (2003). Different time courses for visual perception and action priming. Proceedings of the National Academy of Sciences of the United States of America, 100, 6275-6280.

\footnotetext{
1 The difference in $d^{\prime}$ between both masks computed with the square mask gives a difference of $d^{\prime}=0.79$. The difference computed without this mask results in $d^{\prime}=0.37$.
} 